\title{
Assessing the Prevalence, Causes, and Consequences of Domestic Violence against Women: The Case of Helaba Zone, Southern Ethiopia

\author{
Asebe Awol Amado*
} \\ Lecturer, and Researcher, Dilla University, Ethiopia
}

*Corresponding author: Asebe Awol Amado, Lecturer, and Researcher, Dilla University, Ethiopia, Tel: $+251912058469 / 926123531$

\begin{abstract}
This study aimed to assess, explore and gaining insight into women's experiences of violence in their own words; both qualitative and quantitative approaches are used. Probability and non probability sampling strategies are employed. A total of 146 married women participated in the study. The finding of the study shows that the prevalence of domestic violence in the study area is high. The nature and type of violence are unique and spatial. Husband beating, forced marriage with unmatched age spouse (young girls for elders), the stereotype of girls and women, gender roles that are assigned for only women (all reproductive and productive roles), polygamy, and early marriage are the main ones. The result revealed those women's accounts of abuse is a complex phenomenon because it includes various forms, ranging from humiliation, threats, and social isolation to forced sex and battering. Violence against women runs along with a range, often escalating from milder forms to more serious acts. The finding indicates that physically abusive men are also psychologically and sexually abusive. Low income, low educational level, the difference in marital status, and age were found to be the main cause of domestic violence. Domestic violence has profound consequences on women's overall well-being. The experience of domestic violence puts women at greater risk of physical, psychological, and sexual problems. In general, although domestic violence is a serious problem, it is still largely considered as a 'norm' and private matter. Thus, in Ethiopia by giving visibility to the experience of DV, all stakeholders should work with a positive spirit on the intervention strategies to save the life of women and girls from such severe victims.
\end{abstract}

\section{Keywords}

Domestic violence, Women, Helaba zone and Southern Ethiopia

\section{Introduction}

Domestic violence is now widely recognized as serious human rights abuse and increasingly as an important public health problem with substantial consequences for women's physical, mental, sexual, and reproductive health. The health system often is not adequately addressing the problem of violence and contributing to comprehensive multi-sectorial response [1].

At worldwide, $40-70 \%$ of females murder by their intimate partner. No country in the world is women safe from violence. Domestic violence has gained prominence around the world as a grave violation of human and legal rights. Women are usually the victim of domestic violence that derives from unequal power relationships between men and women [2].

Violence against women and girls is a major health and human rights issue. While rates of women exposed to violence vary from one region to the other, violence against women is a universal phenomenon. In all societies, to a greater or lesser degree, women and girls are subjected to physical, sexual, psychological, and economic abuse that cuts across lines of income, class, and culture. It is one of the most pervasive human rights violations that deny women of their security, equality, dignity, self-worth, and right to enjoy fundamental freedom. Violence against women is present in most countries in the world, cutting across boundaries of culture, class, education, income, ethnicity, and age [3].

Citation: Amado AA (2021) Assessing the Prevalence, Causes, and Consequences of Domestic Violence against Women: The Case of Helaba Zone, Southern Ethiopia. Int J Womens Health Wellness 7:131. doi.org/10.23937/2474-1353/1510131

Accepted: December 24, 2021: Published: December 26, 2021

Copyright: (C) 2021 Amado AA. This is an open-access article distributed under the terms of the Creative Commons Attribution License, which permits unrestricted use, distribution, and reproduction in any medium, provided the original author and source are credited. 
Domestic violence is common in Ethiopia both urban and rural families. About $88 \%$ of rural and $69 \%$ of urban women believes that their husbands have the right to beat them [4]. Approximately, one out of ten women does a victim of abduction, early forced marriage, rape, and marital rape [2]. Marital rape is still not recognized under the criminal code 2005. Ethiopia's government revises family law in 2000 and criminal law in 2005 to protect women's rights. The Criminal Code Article 648 and the EFDR 1995 Constitution Article 35(4) condemn harmful traditional practices. According to the new criminal code, endangering the lives of pregnant women and children through Harmful Traditional Practices, causing bodily injury to pregnant women and children through Harmful Traditional Practices are punishable provisions, which did not feature in the previous code.

The government has accorded particular attention to the issue of gender based violence and the National committee on Traditional Practices in Ethiopia (NCTPE), the Ministry of Women's Affairs (MoWA) and others government bodies are striving towards the elimination of gender based violence and HTPs. Ethiopia ratified many international agreements including conventions including the Convention on the Elimination of all forms of Discrimination Against Women (CEDAW) in 1981. However, there is a paucity of country-wide evidence about domestic violence against women and associated factors in Ethiopia. The prevalence of domestic violence (DV) is increasing with an alarming rate in Southern Nations, Nationalities and peoples of Ethiopia post Covid-19. The region is with diversified ethnic groups, cultural practices, languages and identities. Besides, there are no adequate studies on the issue of DV in Halaba Zone (SNNPR). Therefore, this study attempt to fill these gaps through the analysis of the DV on the lives of women and girls in Halaba Zone, SNNPR of Ethiopia. Conducting such investigations in study area is important to generate information for policy development in order to improvement and control the negative effects of DV on the life of women and girls. Therefore this study gave attention to study DV in the Helaba Zone of southern Nations Nationalities and Peoples Region (SNNPR) of Ethiopia.

\section{Objectives}

This study aimed to assess the Prevalence, Causes, and Consequences of Domestic Violence against Women in Helaba Zone, Southern Ethiopia

\section{Research Methodology}

A community-based cross-sectional research design with qualitative and quantitative approaches was used. In this type of research design, either the entire population or a subset is selected, and from these individuals, data were collected to help answer research questions. It is called cross-sectional because the information that is gathered represents what is going on at only one point in time.

Both quantitative and qualitative research methods were employed. Survey questionnaire, Focus Group Discussion (FGD), key informant interview and personal observations were used. Probability and non-probability sampling strategies are employed. From probability sampling simple random sampling and non-probability purposive sampling strategies are used. Both primary and secondary sources of data were used. The primary data were obtained from the selected key informants by using the general guided key informant interviews. FGDs were conducted with various selected groups of respondents of religious leaders, women and children affairs, gender experts, and women who perform in the cases of domestic violence. The primary data was collected through a questionnaire, key informant interview (KII), and FGD.

The sample size was determined from the whole women households of study area. Women HHs who live in the Halaba Zone, Wera woreda are the study population. Three kebeles (Holegeba Kuke, Choroko, and Chambule) are selected. The surveys utilized a questionnaire administered to 146 married women who are between at the age of 15-49. To determine sample size Yamane's formula 1967 was used. The required sample size was determined at $92 \%$ confidence level, and level of precision (8\%).

$$
n=\frac{N}{1+N(e) 2}=\frac{2277}{1+2277(0.08) 2}=146.21648 \cong 146
$$

Where " $\mathrm{n}$ " is the sample size, " $\mathrm{N}$ " is the population size (total HHs Holegeba Kuke, Choroko, and Chambule), and " $\mathrm{e}$ " is the level of precision.

The study woreda was selected purposively because of the presence of the severe women domestic violence uniformly among all of the kebeles. Secondly among the 18 kebeles that exist in the woreda 3 of them have been selected by the purposive method. Based on the prevalence of DV is high in these kebeles. In the thirdly, 146 sample respondents were selected randomly from the total households of three kebeles based on the probability proportional to size sampling technique. Data were entered and analysed using SPSS version 20 software. Quantitative data were presented as percentage, frequency and logistic-regression. And the qualitative data were analysed and interpreted thematically and the results are presented in narrative form.

\section{Results and Discussion}

\section{Socio-Economic characteristics of the respondents}

The result revealed that $61 \%$ of the respondents were in the age difference with their husbands below 5 years, which constituted $1.36 \%$ of the respondents. The second major age category was 5 to 10 years in which $61 \%$ of the respondents are included. The third 
age difference between women and their husbands is 11 to 15 which is $28.8 \%$ is observed and the final age difference is above 15 years which is with $8.2 \%$ of the respondents. As the respondents reported that the age difference can matter the degree of violence in different ways, the first age difference which is below 10 years which has been taken as a normal type. The respondents at this age confirmed that they can talk transparently about every case which can deserve for domestic violence like physical, sexual, and emotional, but the age difference which is $11-15$ years and above is not normal age where there are challenges for women to discuss with their husbands transparently because of their significant age difference that means they fear their husbands rather than discussing together. Always at this age husband believe that women should respect the need of them. Unless women act out of the need of their husbands they will immediately face domestic violence and became the victim of it (Table 1).

\section{Marital status}

Marital status of the respondents is one of the factors that can matter domestic violence of women. If the woman was married with a large age difference to her husband, there is a probability of being exposed for domestic violence that is why there will not be equal access to discuss with her husband friendly rather than respect and obey his commands patiently.

According to the result of a survey, $140(95 \%)$ of respondents were married, $3(2.5 \%)$ of respondents were divorce and $3(2.5 \%)$ of respondents in the study area were widowed. From the above data, we can conclude that $(95 \%)$ the respondents were married and it was advantageous to get significant information about the DV against women (Table 2).

\section{Nature of marriage}

The study result shows that $71.42 \%$ are monogamous marriage families and the rest $28.5 \%$ are polygamous. Majority of the people in the study area are Islamic religion ideology followers. The prevalence

Table 1: Demographic profile respondents of the age discrepancy.

\begin{tabular}{|l|l|l|}
\hline Age category in years & Frequencies & Percent \\
\hline Below 5 & 2 & 1.36 \\
\hline 5 to 10 & 90 & 61 \\
\hline 11 to 15 & 42 & 28.8 \\
\hline Above 15 & 12 & 8.2 \\
\hline
\end{tabular}

Table 2: Demographic profile of respondents of marital status.

\begin{tabular}{|l|l|l|}
\hline Marital status & Frequencies & Percent \\
\hline Married & 140 & 95 \\
\hline Single & - & - \\
\hline Divorce & 3 & 2.5 \\
\hline Widow & 3 & 2.5 \\
\hline
\end{tabular}

of polygamous marriage is high because their religion allows them to engage in such marriage. The people of the study area believe that Polygamous marriage (more than one wife) is allowed by their religious ideology (Table 3).

The qualitative finding from respondents shows that polygamous marriage has a great effect on the lives of women in the study area. Findings from KKI and FGD are explained as follows:

The economic effects, social, health, psychological, continuous quarrel between the wives in a polygamous, physical attack, inability of parents to properly bear their children, serious conflict among the children, human right violation, school dropout, shortage of balanced diet, lack of proper emotional treatment: love and affection, exposed for delinquent/Antisocial/behavior are the major assessed findings that polygamous marriage households wives and children face. The first wife takes on all socio-economic burdens of her children because the husband is only responsible for the exwife and her children to provide for all socio-economic needs. Due to inadequate and limited access to and over resources, she engaged in different paid and unpaid labor activities to bring her children.

\section{Education}

The survey result indicates that about three of fourth of the respondents (63.7\%) were illiterate, 32.1\% attended elementary school and the remaining $4.1 \%$ had education level above high school.

Education is one of the factors that can matter domestic violence of women. If the woman is educated, she is more likely to know her rights and duties. She will be assertive and free from harmful myths and will defend her rights through all means. It has been shown in the demographic survey that educated women are less likely to agree a man is justified in abusing his wife for any reason compared to uneducated women.

Education is one of the determinants, which influence women's perception towards adoption and assessment of domestic violence against women. Generally, bettereducated women have a more realistic perception about domestic violence problems and have more knowledge to application of domestic violence against women and hence easily handle domestic violence as compared to the uneducated category. In the study area, women have no more opportunity to get an education, the society perceives that women as the only support for her husband, and her role is childbearing only (Table 4).

Table 3: The Nature of marriage of respondents.

\begin{tabular}{|l|l|l|}
\hline Marital status & Frequencies & Percent \\
\hline Monogamous & 100 & 71.42 \\
\hline Polygamous & 40 & 28.58 \\
\hline Total & 140 & 100 \\
\hline
\end{tabular}


FGD explained that sending girls to school is not allowed earlier in society, currently, there is change and improvement. Therefore stakeholders should work on awareness creation to alleviate the violence that restricts the rights of women in the study area (Kuke Kebele resident of FGD participants).

\section{Income}

Concerning income of the respondents 38 in number or $26 \%$ of them can earn income less than 100 birrs per month, 108 or $64 \%$ of my respondents can earn from 100 birrs to 500 birrs but there were not any respondents who can get income beyond to the income mentioned. From this finding, we can conclude that the domestic violence of women is directly interrelated with the amount of income that they can get because of economic independence. In the study area women are responsible only for house chores and men are responsible for home income-generating activities. But also their roles are only reproductive. This study is in line with [5] of Addis Ababa University (Table 5).

\section{The experience of domestic violence}

In the study area, women are punished physically by stick and "along" that are made-up of skin/Hilaire to physical punishment purpose only. The respondents reported that in the study area 119 (81.5\%) of them are victims of such emotional violence through bad namecalling, discrimination, and insult by the respective husband. Most of the respondents accept it as the expression of love from their husbands (Table 6).

\section{Deprived right to choose their marriage partner}

As the respondents claimed that they do not have the right to make a marriage partner without the

Table 4: Profile of respondents of educational level.

\begin{tabular}{|l|l|l|}
\hline Education & Frequencies & Percent \\
\hline Illiterate & 93 & 63.7 \\
\hline Elementary & 47 & 32.1 \\
\hline High school & 6 & 4.2 \\
\hline Diploma & - & - \\
\hline Above & - & - \\
\hline
\end{tabular}

Table 5: Profile of respondents of income.

\begin{tabular}{|l|l|l|}
\hline Income & Frequency & Percent \\
\hline Less than 100 & 38 & 26 \\
\hline $100-500$ & 108 & 64 \\
\hline $501-1000$ & - & - \\
\hline Above 1000 & - & - \\
\hline
\end{tabular}

Table 6: The experience of violence in the study area.

\begin{tabular}{|l|l|l|}
\hline Are you even punished physically? & Frequency & Percent \\
\hline Yes & 119 & 81.5 \\
\hline No & 27 & 18.5 \\
\hline
\end{tabular}

goodwill of their parents. From the total number of respondents in study 131 of them or $89 \%$ reported that spouses have no right to choose their marriage partner with their consent. In the study area, DV is Severe which needs critical attention of both government and other civic societies to make gender equality. Unless it is very difficult to assure Economic, Social and political development through the society (Table 7).

The FGDs participants explained that they were exposed to the physical type of domestic violence that happened like pushed or shoved, beaten that could hurt the respondent, kicked or dragged, shocked or burned, and threatened verbally. As FGDs women are seen as subjects, and all family socio-economic burdens are fall on their shoulders. They worked for 24 hours at home but the husbands are enjoyed with their friends by chewing chat in under trees and moving towns with their friends. Not only this early marriage is practicing in society still. Parents allow their daughters to marry the husband which loves them with unmatched age. If one lost his wife by death even in old age he marries girls under 20 years.

According to KKI women were exposed for sexual violence, they make sexual intercourse without their goodwill or readiness they are forced to have sexual intercourse only for the interest or satisfaction of their husbands. Girls many girls are becoming the victims of early marriage rooted in the custom of society. This study complements the study in Gonder University, Ethiopia, by Mulunesh, et al. [6] which claimed that many women were forced to have sexual intercourse by their husbands without their good will.

\section{The Results and Discussion of the Binary Logit Model}

The output of the logit model showed that six variables were identified as significant out of the hypothesized eleven variables. These are the age of household (Age), income status of the household (income), education of the household (Edu), marital status (MST), Have you ever been insulted (HYBI) or physiological violence by her husband and $\mathrm{A}$ women should be able to choose her friends even if her husband (WSCH) or the right of women to choose her social friends. The goodness of fit confirmed that the model fits the data. The $p$-value shows the overall goodness of fit of the model significant at a $1 \%$ probability level. This indicates the model estimate fits the data at an acceptable level. The other measure of goodness of fit

Table 7: Respondents' right to choose their marriage partner.

\begin{tabular}{|c|l|l|}
\hline $\begin{array}{l}\text { Are you decided to choose } \\
\text { your marriage partner by } \\
\text { yourself? }\end{array}$ & Frequency & Percent \\
\hline Yes & 15 & 11 \\
\hline No & 131 & 89 \\
\hline
\end{tabular}


in the logistic regression model is measured by count $\mathrm{R}^{2}$, which works on the principle that if the predicted probability of the event is greater than 0.80 the event will occur otherwise the event will not occur [7]. The overall prediction of the model is found to be $92 \%$ which is greater than 0.8 it is a probability to be confidents as the social survey research.

The result of maximum likelihood estimates of the binary logit model is presented in Table 7. From the binary logit model, we can conclude the variables as follows:

\section{Age of discrepancy}

The result of the model shows that it is significant by $1 \%$ and will have a positive relation to the probability of occurrences of domestic violence. The sign of this variable is consistent with the prior expectation that means positively and significantly influenced the probability of household age to occur domestic violence.

\section{Income of the respondents}

The result of the model shows that the monthly income per household equivalent is significant at $1 \%$ percent probability level and related positively to have at least equal right and not to be economically dependent and exposed to domestic violence.

\section{The educational level of the respondents}

The result of the model shows that education level had a direct relation with the domestic violence of the residents by 1 percent probability level and it is positively linked. If the level of education is high the women will have a probability of good awareness about the right and responsibility.

\section{Marital status}

It is one of the explanatory or independent variables the result of the model shows that MSt is highly significant with 52.495 chi-squares and with a p-value of 0.004 related to the women's domestic violence. If the marriage event between proper age differences of husband and wife is most probably between 5-10 that is good but beyond that, the probability of domestic violence is harsher according to the finding of the model.

\section{Domestic violence that against women is a form of insult}

The result of the model shows domestic violence that harm women is a form of insult indicates the level of the bad act by husbands which have a direct relation with the domestic violence on women and which is significant by 1 percent probability level and it is positively linked. If the level of women based domestic violence is a form of insult increases the probability of women being exposed to unwanted DV will increase too.

\section{Woman's right to choose their social friends}

The result of the model shows women have no
Table 8: The maximum estimates domestic violence of respondents' binary logit model regression.

\begin{tabular}{|l|l|l|}
\hline Independent Variable & Chi-square & P-value \\
\hline Age discrepancy & 17.979 & 0.015 \\
\hline Education & 25.590 & 0.012 \\
\hline Monthly income & 10.306 & 0.016 \\
\hline Marital status & 52.495 & 0.004 \\
\hline $\begin{array}{l}\text { Women based domestic violence } \\
\text { is a form of insult }\end{array}$ & 13.996 & 0.030 \\
\hline $\begin{array}{l}\text { Woman's right to choose their } \\
\text { social friends }\end{array}$ & 8.097 & 0.044 \\
\hline
\end{tabular}

freedom to choose their own either male or female social friends for different societal collaboration in cases of the study area that means the SPSS result indicates this variable is significant by $1 \%$ and with chi-square of 8.097. This explanatory variable had a direct relation with the domestic violence of the residents and it is positively linked (Table 8).

\section{Conclusion and Recommendations}

\section{Conclusion}

The prevalence of domestic violence is high in Helaba Zone, Southern Ethiopia. The nature and type of violence are unique in the study area. In the study area, the major violence that harms women and girls are, early marriage, marriage with unmatched age level peer, physical violence like beating by husband, polygamy, stereotyping of women and girls regarding education, marriage, and decision making.

In the study area, most of women are exposed to the physical type of domestic violence that happened like pushed or shoved, beaten that could hurt the respondent, kicked or dragged, shocked or burned, and threatened verbally, this indicated that in the study area how women were the victim of DV. The dominant push factors for DV are age, level of income, level of education, and marital status.

\section{Recommendations}

The following recommendations are forwarded based on the finding of the study:

- The Federal and regional governments of Ethiopian should work on to minimize the prevalence DV that against women and girls through legal actions into practice and educative measures on women's rights.

- Women should be empowered, aware and educated about their human and democratic rights.

- Further research is needed on the negative impacts of DV in the area.

\section{References}

1. Koenig MA, Lutalo T, Zhao F, Nalugoda F, Wabwire- 
Mangen F, et al. (2003) Domestic violence in rural Uganda: Evidence from a Community-based study. Bull World Health Organ 81: 53-60.

2. Agumasie S, Bezatu M (2015) Domestic violence against women and associated factors in Ethiopia: Systematic review. Reproductive Health 12: 78.

3. Christiana SZ (2012) Assessment of domestic violence and abuse against women and its effects on a family relationship in four selected local governments in Taraba State, Nigeria.
4. (2005) Ethiopia Demographic Health Survey (EDHS). Central Statistical Agency Addis Ababa, Ethiopia.

5. Sosina M (2016) Domestic Violence against Women: The Case Study.

6. Mulunesh B (2016) The Prevalence and Determinant factors of Gender-based violence against women in North Gondar Zone (The case of Debark Woreda).

7. Madalla GS (1989) Methods of estimation for models review of economics and statistics. 